\title{
REPRESENTACIONES CONTEMPORÁNEAS
}

\section{Contemporary Representations}

Sergio Moyinedo | historiacritica843@gmail.com

Historia del arte VIII y IX

Facultad de Bellas Artes

Universidad Nacional de La Plata

Argentina

Recibido: 17/1/2018

Aceptado: 21/4/2018

\section{RESUMEN}

A lo largo de la historia del arte existieron diferentes modalidades de representación. Luego de las representaciones miméticas de la época clásica y del episodio moderno de autorrepresentación, la contemporaneidad artística presenta nuevos caminos en la construcción de sus referencias temáticas. Bajo esa nueva condición, las obras de distintos artistas recuperan, mediante modalidades contemporáneas, la representación de áreas temáticas propias del arte político o la autobiografía.

\section{PALABRAS CLAVE}

Representación; arte; contemporaneidad

\section{ABSTRACT}

Throughout the history of art there were different modes of representation. After the mimetic representations of the classical period and the modern episode of selfrepresentation, artistic contemporaneity presents new paths in the construction of its thematic references. Under this new condition, the works of art of different artists recover, through contemporary modalities, the representation of thematic areas typical of political art or autobiography.

\section{KEYWORDS}

Representation; art; contemporaneity 


\section{CÓMO MIRAR}

Podemos mirar una obra de arte o mirar cómo se mira una obra. Aquí, previsiblemente, elegiremos la segunda opción. Las palabras que siguen apuntan, más que nada y de manera general, al problema del análisis. Abordaremos esa problemática considerando modalidades de la representación artística que reintroducen, mediante procedimientos contemporáneos, la referencia a los distintos aspectos del mundo.

\section{CLÁSICO Y MODERNO}

Es posible afirmar, sin mucho riesgo, que el arte, en la mayor parte de su historia y de su geografía, se dedicó a representar. La historia del arte, especialmente de las artes visuales, tuvo como una de sus principales preocupaciones contrastar las cambiantes modalidades de ese representar. La imagen de un hombre que escucha la brisa entre los pinos realizada en tinta sobre seda en la China del siglo XIII y un paisaje pintado en Holanda del siglo XVII comparten la misma voluntad de representación basada en la semejanza. Esta voluntad involucra tanto al artista como al espectador arrastrándolos en una lógica de transparencia que vincula la imagen con el mundo mediante unos pocos, delicados e invisibles hilos. Una tela pintada se asemeja muy poco al mundo que quiere mostrar, por eso a los mejores pintores se les celebra -o se les celebró- por su minuciosa habilidad para construir el puente que conecta la representación con lo representado. Pero no olvidemos que la puesta en marcha de la maquinaria representativa -en el caso de la mímesis o en cualquier otro- no se agota en la actividad del artista, sino que presupone unas instrucciones de uso que determinan hábitos de lectura. El espectador es también autor de la representación que activa en el momento en que ejecuta las habilidades cognitivas específicas y necesarias para que la ilusión de semejanza se manifieste. Subrayemos, por las dudas, esta última idea: el espectador ocupa siempre una posición productiva en relación con una representación, sea artística o no.

Más cerca en el tiempo, la crisis moderna degrada a la mímesis artística de rasgo necesario a rasgo facultativo. El arte moderno se define por la reflexividad manifiesta de sus obras $y$, a partir de ese cambio, se delimitan nuevas figuras de artista y de espectador. El pintor moderno ya no es el magistral artesano del teatro del mundo y las habilidades de la semejanza dejan de ser imprescindibles. Artista y espectador, en tanto modernos, inician una nueva conversación en la que el aspecto visible del mundo es un tema secundario; se trata ahora de una conversación sobre el propio mundo del arte, sus límites, 
1 Es sobre ese fondo narrativo que Picasso se hace moderno, reconociendo y negando al mismo tiempo los imperativos miméticos de la época anterior. El viejo espectador mimético, desajustado narrativamente, se estrella contra un retrato analítico y se escandaliza por la impericia insultante del artista.

2 El tercero del que hablamos aquí es aquel término necesario para que se cierre una relación de referencia; se trata de un sabe habitual y compartido que permite vincular la representación con lo representado. La hipótesis que nos guía aquí es que cualquier representación, lejos de producirse naturalmente, demanda una actualización de saberes específicos determinados históricamente. Así, por ejemplo, el efecto testimonial de una representación fotográfica solo se manifiesta en presencia de un saber acerca del funcionamiento del dispositivo fotográfico. Evidentemente, esta idea de tercero también se relaciona directamente con la noción de Interpretante tal como la concibió Charles Peirce (1974). sus técnicas, sus géneros, sus maneras, su historia. Se definen nuevos saberes compartidos, nuevas habilidades productivas, nuevos hábitos de lectura. Estos nuevos usuarios del arte podrían entrar -tomando una imagen formulada por Gérard Genette- en la categoría de "aficionados ilustrados» (Genette, 1997, p. 159). Los espectadores modernos, diferentes de los miméticos, comprenden que un retrato analítico de Picasso no es un retrato, pero tampoco un error o una burla, sino la invitación a un juego reflexivo sobre los géneros de la pintura. Saben que Picasso está jugando con la representación.

\section{REPRESENTACIÓN}

No siempre hay representación. La representación involucra un cuándo y un dónde, no es una cualidad intrínseca de ciertas cosas sino el estado de un sistema, el efecto de una relación. De ahí que la actividad representativa pueda desencadenarse a partir de cualquier materialidad dependiendo de las modalidades semióticas en que una cosa se presente en lugar de otra. Esas modalidades semióticas ponen a funcionar la representación a partir de operaciones tanto productivas como de reconocimiento (Verón, 1987). En el paisaje del siglo XVII mencionado antes, no es solo el artista quien cuenta la historia de ese espacio natural admirable al poner en obra las delicadas operaciones de la semejanza, sino también el espectador al actualizar saberes específicos que forman parte de un horizonte narrativo compartido. ${ }^{1}$ Por su parte, existen, como veremos más adelante, modalidades de representación artística distintas de la que aquí llamamos mimética y que requieren el ajuste a funcionamientos semióticos diferentes de los que regulan la representación por semejanza.

Es oportuno introducir la idea de que toda relación de representación involucra una operación necesaria para cerrar la distancia entre la representación y lo representado, vinculando de alguna manera esos mundos heterogéneos. Ese cierre requiere de «un tercero para pasar el abismo, cicatrizar la apertura y pensar la diferencia» (Derrida, 2001, p. 47). La maquinaria representativa se activa en presencia de un tercero ${ }^{2}$ que, en el mundo del arte, se materializa como sistemas de textualidades heterogéneas y específicas presentes, por ejemplo, en el espacio de una exposición. Estas textualidades -en forma de carteles, videos, configuraciones del espacio arquitectónico, audioguías, etcétera- van a posibilitar el funcionamiento representativo de ciertas obras. 


\section{CÓMO CONTAR COSAS SIN PALABRAS}

No se puede. Aunque sí sería posible contar una historia utilizando objetos, siempre y cuando haya -más o menos cerca en el tiempo y en el espacio-, además, palabras. Palabras escritas, oídas, sabidas. Incluso, cuando solo hay imagen también hay palabra: las secuencias de imágenes didácticas medievales no tendrían sentido para alguien que no hubiese escuchado antes contar la historia sagrada del cristianismo. Un poco más acá en el tiempo, un objeto depositado en el piso de una galería de arte puede contar muchas historias; pero eso dependerá del sistema textual que lo acoja. El sistema textual vinculado a la exposición artística de un objeto o de un conjunto de objetos tiene múltiples dimensiones. En el caso concreto de una exposición como las que vamos a describir más adelante, el estatuto representativo de los objetos y su funcionamiento temático están determinados por un sistema paratextual (Genette, 2001) que coexiste con las materialidades presentadas como obra. Esos textos que involucran diferentes formatos y tecnologías proveen saberes específicos que incluyen a los objetos en una trama narrativa que define su funcionamiento representativo.

\section{CONTEMPORÁNEO}

En una conversación sobre el arte contemporáneo no es raro escuchar la afirmación de que la obra contemporánea necesita de muchas explicaciones. Es cierto, pero también es cierto que el arte de toda época requirió de saberes específicos. La representación mimética funcionó a partir de un conocimiento generalizado acerca de las posibilidades de la semejanza y, por su parte, la apreciación de la obra moderna estuvo determinada por una actividad reflexiva compartida. En cuanto al arte contemporáneo, pareciera que, en muchas de sus obras, las posibilidades de lectura en términos representacionales no dependen ya de un saber generalizado. Es como si cada obra formulase sus propias reglas de juego. Ya no se trata de un saber de época y de clase acerca de la historia religiosa, ni de un saber, también de época y de clase, acerca del mundo del arte compartido por un grupo de "aficionados ilustrados», sino de saberes materializados en sistemas textuales heterogéneos que formulan teorías ad-hoc para cada obra.

\section{A PROPÓSITO DE UNA REEERENCIA POLITICA}

Miles o millones de réplicas de semillas de girasol en porcelana pintada yacen en el piso de la sala de un museo de arte. Esa inclusión 
3 El término umbral es utilizado por Gérard Genette para referirse al sistema paratextual que acompaña a todo texto: «El texto raramente se presenta desnudo, sin el refuerzo o el acompañamiento de un cierto número de producciones, verbales o no [...] [que] lo rodean y lo prolongan precisamente por presentarlo, en el sentido habitual de la palabra, pero también en su sentido más fuerte: por darle presencia por asegurar su existencia en el mundo, su "recepción" y su consumación» (2001, p. 7).

4 «In 1998I had a complete, absolute breakdown and I spent four days in bed; I was asleep and semi-unconscious. When I eventually did get out of bed, I had some water, went back, looked at the bedroom and couldn't believe what I could see; this absolute mess and decay of my life, and then I saw the bed out of that context of this tiny, tiny, bedroom, and I saw it in just like a big, white space. I realised that I had to move the bed and everything into the gallery space» (Emin, 2015, s/p). Traducción del autor del artículo.

5 Aunque fue objeto de una recepción moderna escandalizada por la presentación obscena de una cama pringosa como obra de arte. institucional ajusta, de entrada, las expectativas del visitante al ámbito de las prácticas artísticas. Previsiblemente, en su deambular por la sala, el espectador pasa por una instancia de ajuste temático de la obra. Un cartel, un video documental o la voz de la audioguía suministran la dosis pratextual suficiente para poner en marcha la maquinaria representativa. Se revela el origen de las réplicas y la relación que el artista Ai Weiwei encuentra entre las semillas de girasol y la situación política en China durante la Revolución cultural de Mao Zedong. El acceso al centro temático de la obra queda así franqueado y la referencia se despliega como relación no mimética entre la acumulación de las réplicas y la dimensión política del mundo. Cualquier lectura sería legítima, un espectador niño, por ejemplo, que aún no sabe leer, ajustará la percepción de las falsas semillas a sus propias expectativas sobre el funcionamiento del mundo. Pero la parafernalia curatorial de la institución trabaja sobre otra hipótesis de lectura que inscribe la obra de Ai Weiwei dentro de las fronteras de lo que se suele denominar arte político. Parece imposible que un visitante pueda acceder a esas referencias si no atraviesa el umbral ${ }^{3}$ discursivo que se le ha construido.

\section{MY BED}

\section{En 1998 sufrí un absoluto colapso nervioso y pasé cuatro días en la cama dormida y semi-incosciente. Cuando finalmente me levanté, tomé un poco de agua, volví, y al ver el cuarto no podía creer lo que veía: el absoluto caos y decadencia que era mi vida; luego vi la cama fuera del contex to de ese pequeño, diminuto cuarto y lo percibí como un gran espacio blanco. Comprendí que tenía que mover la cama y todo lo demás al espacio de la galería (Emin, 2015, s/p). ${ }^{4}$}

Con estas palabras, Tracey Emin relata el origen de una de sus obras más conocidas. Emin finalmente cumplió con su visión y trasladó su cama, con todos los desechos generados durante esos cuatro días, a una sala de exhibición. Lo primero que habría que aclarar es que no se trató de un Ready-made; este tipo de presentación de un objeto está lejos de la conversación moderna acerca de los límites del arte ${ }^{5}$ y, en cierta manera, más cerca de prácticas representativas tradicionales. La presencia de esa cama en la sala de exhibición no respondió a las necesidades reflexivas de la modernidad, la cama estaba allí para representar. Durante los cuatro días que duró el breakdown, la cama de Tracey Emin no representó ni se encontró investida de un estatuto artístico. Fue su emplazamiento en una sala de arte lo que la dispuso

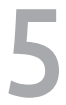


para una lectura artística y lo que ajustó, además, su funcionamiento en modo representativo: no estaba allí para ser admirada por su diseño sino para contar una historia. Esa cama que antes no representaba —que no estaba en representación - en ese espacio representó; y esa cama, que antes era la copia de otras camas, pasó a ser única. ${ }^{6}$ Una vez definida su función artística por relocalización y por inclusión institucional, quedó enganchada narrativamente en una lógica autobiográfica.

La cama se exhibió con «todos sus desperdicios, las botellas, las sábanas cagadas, las manchas de vómito, los condones usados, la ropa interior sucia, los periódicos viejos» (Emin, 1998, s/p). ${ }^{7}$ La representación concretó allí por vía indicial: los objetos funcionaron como fragmentos de un pasado vivido que retornó. El lazo con ese pasado biográfico se tensó en presencia de un tercero paratextual que determinó el funcionamiento semiótico de la materia ofrecida al espectador convirtiéndola en reliquia de una historia personal. ¿Y si la historia es falsa?, ¿y si esa cama jamás estuvo en la casa de Emin?: sostener la ilusión representativa es el objetivo de la poderosa maquinaria textual de la exhibición. ${ }^{8}$

\section{CONCLUSIÓN}

El ejemplo de la cama de Tracey Emin resulta útil para pensar modalidades contemporáneas de la representación. Lo interesante de ese ejemplo, y del de Ai Weiwei, es que pone en el centro de la discusión el carácter no natural ni evidente de la representación. Como espectadores, tal vez nos quedemos perplejos frente a estos objetos mudos hasta que una indicación oportuna los encienda como una pantalla o los transparente como una ventana, convirtiéndolos en superficies de reenvío al mundo. Las referencias políticas o biográficas se desencadenan a partir de ese tercero paratextual y recuperan formatos genéricos de larga historia para las artes visuales, bajo una nueva apariencia.

\section{REFERENCIAS}

Derrida, J. (2001). Parergon. En La verdad en pintura (pp. 49-153). Buenos Aires, Argentina: Paidós.

Emin, T. (1998). My bed [Foto de la obra]. Recuperado de http://www. christies.com/presscenter/pdf/2014/RELEASE_TRACEY_EMINS_MY_ BED.pdf

\footnotetext{
6 Para ampliar la idea de relocalización y reauratización de la copia, se sugiere ver La topología del arte contemporáneo» (2009), de Boris Groys.
}

\footnotetext{
7 "All its detritus, with all the bottles, the shitty sheets, the vomit stains, the used condoms, the dirty underwear, the old newspapers» (Emin, 1998, s/p). Traducción del autor del artículo.
} 
Emin, T. (2015). My bed [video]. Recuperado de http://www.tate.org. uk/art/artworks/emin-my-bed-l03662/tracey-emin-my-bed

Genette, G. (1997). El estado conceptual. En La obra del arte (pp. 15578). Barcelona, España: Lumen.

Genette, G. (2001). Umbrales. Ciudad de México, México: Siglo Veintiuno.

Groys, B. (2009). La topología del arte contemporáneo. Recuperado de <http://lapizynube.blogspot.com.ar/2009/05/boris-groys-latopologia-del-arte_175.html

Peirce, Ch. (1974). La ciencia de la semiótica. Buenos Aires, Argentina: Nueva Visión.

Verón, E. (1987). La semiosis social. Fragmentos de una teoría de la discursividad. Buenos Aires, Argentina: Gedisa. 